\title{
Level of integration of the digital transformation of the supply chain in Moroccan companies
}

\author{
Heddoun Asmae \\ National School of Commerce and \\ Management -Tanger Morocco \\ Research Group: Strategy, \\ Management and Governance \\ heddoun.asmae@gmail.com
}

\author{
Benrezzouq Rhizlane \\ National School of Commerce and \\ Management -Tanger Morocco \\ Research Group: Strategy, \\ Management and Governance \\ benrezzouq.rhizlane@gmail.com
}

\begin{abstract}
Successful digital transformation requires a holistic approach to the partners as a whole - from suppliers of raw materials to manufacturers and distributors to logistics and transport service providers. in this context that our research is based, it is to explore the level of integration of the digital transformation of the supply chain in Moroccan companies. We will try to answer the following question: What is the level of integration of the digital transformation of the supply chain in Moroccan companies?
\end{abstract}

Keywords-Partner, Supply Chain, Digital Transformation, Information Flow, Agility

\section{PREFACE}

The digital transformation of the supply chain is today a key trend in the business world, which has already been the subject of much research. Most studies have touched on digital transformation within organizations or between organizations and their clients.

The supply chain continues to grow and is a major response to the challenges of the current changes in the business environment both in Morocco and elsewhere.

One wonders what the expression "digital transformation" means [1]? It refers to the many changes that the digital technology boom is imposing on our society. In a world where the flow of goods and information continues to grow and accelerate, companies face a real challenge. They must indeed integrate these new technologies in order to evolve their organization and their logistics to develop the agility of the Supply Chain.

The digital transformation [4] becomes synonymous with profitability and competitiveness by the benefits it brings: customer service, quality, dematerialization, fluidification of information, traceability, acceleration of financial flows, etc.

Interactions between organizations in a network are as important as interactions within these organizations. This can be access and sharing of data, or collaboration and analysis across the entire network

\section{LITERATURE REVIEW}

\section{A. Digital Transformation: Basic Theory}

In a now famous article [5], Markus and Robey 1988 propose a typology allowing to identify a priori the three great epistemological postures allowing to apprehend the nature of the interaction in information technology and communication and organization. in particular, to synthesize the contributions of Peffer 1982 on the causal articulation and the level of analysis and those of Mohr 1982 on the logical structure. in short, the causal articulation sends to the nature of causality. Is the initial impulse exogenous or endogenous? thus, either external forces are the cause of the change (technological imperative), or the man acts voluntarily to accomplish fixed objectives (organizational imperative) or the change is the fruit of the interaction between the man and the events ( perspective of emergence). the logical structure refers to the temporal horizon of the theory [6] (static or dynamic) and the hypotheses on the causal relationship.

These hypotheses [7] are similar to those found in variance and process theories. either the causes are related to the effects by an invariant relation and necessary and sufficient conditions, or the conditions are necessary but insufficient to cause the effect after a certain time. In fact, the form of causal articulation is the major epistemological question underlying the modeling choices of the organization's technologystructure interaction and which, more generally, makes it possible to better understand the different academic positions.

In the deterministic approach [8], the evolution of the environment requires the adoption of technologies whose technical characteristics inevitably have a precise impact on the organization. Determination is therefore technological in the sense that the initial impulse is essentially technical and of exogenous origin. This is the case for radical innovations whose effects can be observed as soon as the technology is introduced. This perspective is generally discussed either through historical analyzes that highlight a strong link between organizational transformations and ICT diffusion or by theoretical constructs that rely on the properties of ICTs

In the engineering approach [9], ICTs can not play on the organization since they result. This perspective aims to specify the structural attributes and ICTs that best respond to it: ICTs are dependent on design choices. The organization is considered as an information processing system whose efficiency and effectiveness require to find the right balance between its information processing capacity and the information burden caused by the environment. that is, its information processing needs. Although using a capacity to manage the finalized action, the engineering approach uses most of the time the contextual determinism of structural contingency theories. 
Finally, the emerging approach [10] considers that the real question is not so much that of the meaning of the relationship between technology and structure, but that of the role of the users. In the framework of analysis thus defined, these are the characteristics users, their perception of the tools and the social influences they generate which explain the uses and associated organizational transformations (Jameux, 1989). By reintroducing individuals, their interpretations and corporate culture into the communicative field, this approach requires careful observation of the actual use of ICTs. Inspired in particular by Weick (1969) [11], this approach focuses on the in-depth analysis of processes such as perception and the creation of meaning for the understanding of organizational phenomena.

By nature, the technological and organizational changes [12] in which businesses operate are often more opaque and less easily interpretable than those of civil society. It is therefore more difficult to know these transformations: external statistical identification is often insufficient to understand complex and multifaceted evolutions. Only direct inquiries make it possible to be aware of these evolutions, to understand and to interpret a phenomenon which always has a singular character. It is precisely this "repetition of the singular" that will allow Venkatraman (1995) [13] to conceptualize from a dozen case studies carried out in the course of the 1990s the different levels of business reconfiguration caused by ICT.

These hypotheses [7] are similar to those found in variance and process theories. either the causes are related to the effects by an invariant relation and necessary and sufficient conditions, or the conditions are necessary but insufficient to cause the effect after a certain time. In fact, the form of causal articulation is the major epistemological question underlying the modeling choices of the organization's technologystructure interaction and which, more generally, makes it possible to better understand the different academic positions.

\section{B. Digital Transformation: A historical perspective}

The notion of digital transformation [14] appeared in 2000 is more and more pregnant because of the speed of the transformation in progress. Under the pressure of new entrants, to adapt to new consumer behavior or to take advantage of technological tools in terms of innovation or productivity, companies are called to rethink their processes or the way they interact with their parties. stakeholders.

It should be noted at this stage that managers and decisionmakers often have limited knowledge of what digital transformation is, [15] what it represents, and the tools and methods to take advantage of it. Harvard [16] points to the lack of agility of the IT departments of large companies and their lack of strategic vision. In France, there is a significant lack of activity in many companies in the face of a future unexpected event. The attitude (pathological) generally adopted is "as we do not know exactly what is waiting for us and everything evolves so fast, we prefer not to do anything! ". But to do nothing is to die! The main challenge [17] is to be a player in this change and make the most of the potential of this unexpected. We must see in this unexpected opportunities rather than threats. This question concerning the posture or the state of mind of managers and leaders in the face of change occupies a significant place in academic research in strategy because digital transformation is above all a question of strategy [18].

\section{THE AGILITY OF THE SUPPLY CHAIN}

\section{A. From Logistics to supply chain}

Logistics traditionally represented the activity ranging from the provision of finished products by the factory or the merchant to delivery to the customer. It has now merged into the concept of "Supply Chain Management" or SCM, the French Supply Chain whose objective is to optimize the management of physical flows and information flows along the supply chain. from the supplier of the supplier to the customer of the customer.

It is therefore present at all levels of the company, both at the operational level - for the management of physical flows of goods, for example - at the tactical level - to define the organizations and to manage these flows in the medium term - strategic - to define long-term trends.

Planning all the activity of the company, purchasing, production and distribution of products, based on customer demand, this could be a synthetic definition of the optimization of the "supply chain".

The "Supply Chain" is not a function of the company, nor is it a service that can be purchased from a service provider, it is not a computer module, it is in fact an operating procedure which aims to ensure the management and synchronization of all the processes that allows one or more customer / supplier systems to take into account and meet the expectations of the end customers (from the supplier of the supplier to the customer of the customer) ".

The "Supply Chain" contains all the activities associated with the flow and transformation of goods, from the raw materials to the finished product delivered to the user, as well as the associated information flows.

"Twenty years ago, the supply chain consisted of pushing pallets and filling trucks, but today, it is a real differentiator," says Mathieu Genoud, director of supply chain strategy at Deloitte. And for good reason: a study conducted by the audit and consulting firm notes that $79 \%$ of organizations with a high-performance supply chain generate a growth in turnover well above the average of their sector." How can a company move from being a "follower" to a "leader" in this field?

Deloitte lists five success factors. First, the presence of a representative of the supply chain to the board. "This makes it possible to align the priorities of supply chain management with the overall strategy of the company and to make it an influential vector," notes Mathieu Genoud. A vector that supply chain leaders segment according to products, customers and channels. "The supply chain then becomes value-creating, explains Nicolas Gaultier, consulting partner supply chain strategy at Deloitte. Leaders adapt their levers delivery mode, purchasing strategies, production or storage, product flow - according to different needs, without uniformity. "

\section{B. The Keys to the agile Supply Chain}

The agility of the Supply Chain is its ability to return to stable operation after a disruption. To this end, it must be able to restore all flows as quickly as possible to minimize the deterioration of the various performance indicators. 
Far from being content to manage the warehouse and shipments, Supply Chain management must interfere in all strategic decisions.

\section{Reduce the sources of vulnerability}

It sounds simple but involves a real reflection on all the company's activities and management decisions. Is it reasonable to rely on a single supplier in a country with a very unstable political system? Does working with several transport companies not reduce the risk of interruption of logistics flows? Many questions to ask to ensure the robustness of the supply chain.

\section{Prepare the organization}

Supply Chain Risk Management managers must strive to prepare the organization to face change. No question of wasting time thinking about a disturbance, a clear procedure understood by all must allow a passage to immediate action. This implies adapting the organizational structure of the company and requires close collaboration between the different departments. In the same way, it becomes imperative to develop privileged relations with customers and suppliers by sharing in particular the exploitation of many data essential to a fast and relevant decision-making.

At leading companies, the supply chain plays an integrating role between the different functions of the company and organizes a strong collaboration with internal functions - from strategy to finance and marketing. "It can even allow the development of a business-provider ecosystem and business-customer, with a logic of risk sharing," says Nicolas Gauthier.

Risks that require the best supply chain to be agile and resilient. "For example, after the 2004 tsunami, Toyota's production was disrupted for six months," explains Nicolas Gaulthier. From now on, thanks to the improvement of its supply chain, the group makes a commitment that the disturbed period in such a case does not exceed six weeks. "A factor of sustainable growth of the company, which, among the best, is reflected in an innovation policy that is positioned at the heart of the supply chain. "It becomes a vector in the change of business model of a company," says Mathieu Genoud. It seems far from the time of simple handling.

\section{CONCLUSION}

The advancements in information technology that have marked the daily life of the company have not been without impact on many industrial and commercial disciplines.

The supply chain, for its part, is a rapidly changing discipline that has taken advantage of the possibilities of automation, acquisition, transmission and data processing to reposition itself within the company as a strategic business, beyond the roles execution that was reserved for him. Thus, the supply chain is more and more interested in medium and long-term considerations. Hence the need for processes, skills and tools to help planning.

The advent of new technologies and its invasion of the world of logistics offer opportunities for cost optimization and improved customer service that were not possible a few decades ago thanks to the improved visibility and transfer of the real-time information that is the first fruit of this marriage between the discipline of new technology and the discipline of the supply chain.

The objective of this study is to know the level of integration of the digitization of the supply chain in companies located in Morocco.

Regarding the data analysis part, we will present the statistical data in the definitive article.

\section{REFERENCES}

[1] Allab (S1.), Talandier (D.), Swyngedauw (N.), Logistics and New Information and Communication Technologies, 2000, 172 p.

[2] Baglin (G.), Bruel (O.), Garreau (A), Greif (M.), Industrial Management and Logistics: Design and Management of the Supply Chain, 2007, $750 \mathrm{p}$.

[3] Camman (Ch.), Livolsi (L.) and Roussat (Ch.), Logistics simply Activities, issues, vocabulary, 2007, 220 p.

[4] Christopher (M.), Supply Chain Management: Creating High Value Networks, 2005, 318 p.

[5] Cohen (Sh.), Roussel (J.), Supply Chain Advantage: The 5 levers to make your Supply Chain a competitive asset, 2005, $406 \mathrm{p}$.

[6] Damiens (J.), the logistical asset - from global logistics to the "Supply Chain": the new asset of the industrial and commercial enterprise, 2007.

[7] Dornier (Ph.D.) and Fender (M.), Global Logistics and Supply Chain Management - Issues - Principles - Examples, 2007, 502 p

[8] Epinette (G.), Leboucher (B.) and Martin (P.-D.), eSCM and IT sourcing, the reference framework of the customer-supplier relationship, 2009, $274 \mathrm{p}$.

[9] Fabbe-Costes (N.) and Lièvre (P.), Orders and Disorders in Logistics, 2003, 224 p. Grisot (J.-R.), Practicing Transportation Safety and Logistics, 2003, 80 p.

[10] Hohmann (Ch.), Combined audit - Quality / Supply Chain - Securing customer relationships, 2004, $255 \mathrm{p}$

[11] The Goff (J.), Bensebaa (F.), Measuring the performance of the logistic function, 2009, $220 \mathrm{p}$.

[12] Paché (G.), Spalanzani (Al.), Management of multi-stakeholder logistics chains: strategic perspectives, 2007, 256 p.

[13] Samii (Al.-K.), Logistics Strategy - Supply Chain Management: Foundations - Methods -Applications, 2004, 320 p.

[14] Simonot (P.-Y.), Roure (J.), Collaborative logistics: a question of the future, 2007, $260 \mathrm{p}$.

[15] A. Tricot and P. Et-comtat, The Search for Information as Dialogue, The Digital Books, pp.15-38, 2012.

[16] Sandrine Baslé, ilem - Geneva - Lausanne - Switzerland - Morocco France: "Digital transformation: training, management ... companies are lagging behind! »2016

[17] J. Manyika, M. Chui, B. Brown, J. Bughin, R. Dobbs et al., Big data: The next frontier for innovation, competition and productivity, 2011.

[18] Desfriches-doria and M. Et-zacklad, Improving Information Retrieval Using Thesaurus "Ad Hoc, Experiments and Methodological Reflections, pp.13-40, 2010.

[19] Handfiels \& Straight 2004, how is your supply chain, 89th annual international supply chain

[20] Jones 1985 Physical Distribution and Materials Management

[21] Van Weele 2008 Purshaing and supply chain management, Thomson 4th edition pp157-166

[22] Johan Hagberg, Malin Sundstrom, Niklas Egels-Zandén, (2016) "The digitalization of retailing: an exploratory framework", International Journal of Retail \& Distribution Management, Vol. 44 Issue: 7, pp. 694-712

[23] Digital Mobility as a solution to the efficiency of Veronica STEFAN, pp -19-29

[24] Nicolas Gaultier, The keys to success of the "supply chain" partner consulting supply chain strategy at Deloitte, 2016 